Esta revista forma parte del acervo de la Biblioteca Jurídica Virtual del Instituto de Investigaciones Jurídicas de la UNAM

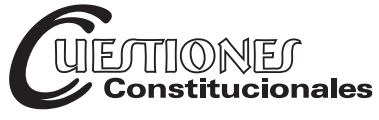

Revista Mexicana de Derecho Constitucional Núm. 44, Enero-Junio 2021

ISSN (versión electrónica): 2448-4881

\title{
¿Es posible la alianza entre el aborto legal y el federalismo?
}

\author{
Is the alliance between legal abortion \\ and federalism possible?
}

Recepción: 1 de marzo del 2020

Aceptación: 1 de septiembre del 2020

\author{
Verónica M. GÓMEZ*
}

RESUMEN: El rechazo del Senado argentino al proyecto de aborto legal, seguro y gratuito que, en 2018, terminó en el archivo de la iniciativa antes aprobada por la Cámara de Diputados, alentó las miradas críticas hacia la composición contramayoritaria de aquel órgano, característico del sistema federal de ese país.

Con base en distintas fuentes, este trabajo relativiza la incidencia de las particularidades del Senado en tal desenlace y problematiza el sobredimensionamiento de las causas vinculadas al diseño institucional por entender que relega la investigación de los argumentos ideológicos, jurídicos, religiosos y científicos que sostuvieron la criminalización del aborto, los actores detrás de esa posición y su capacidad de influir en múltiples esferas de poder, sin limitaciones territoriales.
ABSTRACT: The Argentine Senate's rejection of the legal, safe, and free abortion project that, in 2018, ended up in the archive of the initiative previously approved by the Chamber of Deputies, encouraged critical views towards the counter-majority composition of that body, characteristic of the federal system of that country.

Based on different sources, this work relativizes the impact of the Senate's particularities in such outcome and problematizes the oversizing of the causes linked to the institutional design by understanding that it relegates the investigation of the ideological, legal, religious, and scientific arguments that sustained the criminalization of abortion, the actors behind that position and their ability to exert their influence on multiple spheres of power, without territorial limitations.

* Abogada con estudios de posgrado en género y derecho de la Universidad de Buenos Aires; maestranda en derecho constitucional y derechos humanos de la Universidad de Palermo. Argentina. Correo electrónico: veronicamgomez@hotmail.com ORCID: 0000-0003-2147-0549. 
Esta revista forma parte del acervo de la Biblioteca Jurídica Virtual del Instituto de Investigaciones Jurídicas de la UNAM

Por último, considera contraproducente centrar el análisis en esos aspectos del federalismo e ignorar otras facetas susceptibles de contribuir al avance de la lucha del movimiento feminista por la interrupción legal del embarazo.

Palabras clave: federalismo, senado, aborto, género.
Finally, it considers counterproductive to focus the analysis on those aspects of federalism and ignore other facets that can contribute to advancing in the struggle of the feminist movement for the legal interruption of pregnancy.

Keywords: federalism, senate, abortion, gende.

\begin{abstract}
SUMARIO: I. Introducción. II. El tratamiento de la legalización del aborto en el Senado. III. Las razones y actores detrás de la criminalización del aborto. IV. Aportes del federalismo al debate del aborto legal. V. Reflexiones finales. VI. Fuentes consultadas.
\end{abstract}

\title{
I. INTRODUCCIÓN
}

La estructura bicameral del Poder Legislativo es uno de los rasgos característicos del Estado federal que tiene como finalidad encausar la participación de las unidades territoriales que lo integran en la formación de la voluntad federal (Fernández Segado, 2002: 133). A la distribución de competencias entre distintos niveles de gobierno a partir de la cual es costumbre definir al federalismo (Dahl, 1983: 95), se suma la conformación de una Cámara Alta o Senado que representa a los Estados miembros y convive con una Cámara de Diputados o Sala de Representantes a través de la que se expresa la ciudadanía.

Ese diseño institucional tiene especial importancia en el caso argentino donde nace como respuesta a las marcadas asimetrías de poder político y económico existentes entre las provincias, en tanto herramienta pensada para asegurar la influencia de las jurisdicciones más débiles en el gobierno central y contrarrestar el dominio Buenos Aires (Gibson y Falleti, 2004: 227). ${ }^{1}$

1 La institución senatorial también aparece en los orígenes de otros sistemas federales de la región como el mexicano, donde ha estado presente desde la Constitución de 1824 y distintos estudios la vinculan a la necesidad de mantener la unidad de la comunidad política que, cohesionada bajo el dominio español, corría riesgos de desintegrarse con la independencia (Rivera Suárez, J. y Rivera Suárez, M., 2014: 128 y 134).

Cuestiones Constitucionales, Núm. 44, Enero-Junio 2021

ISSN: $2448-4881$ 
Esta revista forma parte del acervo de la Biblioteca Jurídica Virtual del Instituto de Investigaciones Jurídicas de la UNAM

Así se desprende del pensamiento alberdiano ${ }^{2}$ que, en defensa de la división del cuerpo legislativo general en dos Cámaras, destaca la necesidad de una instancia destinada a representar a las provincias en su soberanía local a fin de reconocer que "son iguales como cuerpos políticos" y tienen los mismos derechos a pesar de sus diferencias territoriales, poblacionales y de riqueza (Alberdi, 2017, XXII). Dicha concepción se ha visto reflejada en el texto constitucional argentino que, aún tras la última reforma sancionada en 1994, continúa asignando a cada jurisdicción provincial, independientemente de su población, la misma cantidad de lugares en el Senado.

Sin embargo, desde una perspectiva diferente, suele llamarse la atención respecto a que esa equiparación de las representaciones territoriales encierra un alto peligro demo-restrictivo agravado porque al Senado se le otorgan atribuciones similares a las de la otra Cámara (Stepan, 1998: 19). En consecuencia, se asume al federalismo como un límite a la premisa democrática de la igualdad sintetizada en la fórmula "una persona, un voto" que, en contraposición, sí se vería garantizada en la Cámara de Diputados donde la unidad de representación es el ciudadano o la ciudadana individual (Gibson, 2004: 21) y, por ende, las bancas correspondientes a las provincias se establecen de acuerdo con la cantidad de habitantes de cada una. ${ }^{3}$

Cuando en agosto de 2018, el Senado argentino rechazó por 38 votos negativos contra 31 a favor, el proyecto de aborto legal, seguro y gratuito que, impulsado por el movimiento feminista, meses antes había obtenido media sanción de la Cámara de Diputados, no faltaron las miradas que bajo este último encuadre teórico, vislumbraron en la composición con-

2 La frase alude a las ideas de Juan Bautista Alberdi sintetizadas en su obra "Bases y puntos de partida para la organización nacional", que inspiraron los debates y sirvieron de antecedente al texto de la Constitución Nacional Argentina de 1853. Aunque este abogado e intelectual porteño no era un ferviente federalista, proponía crear una doble esfera de autoridad política y consideraba a las autonomías provinciales como una forma de reconocer el poder de los gobernadores, pero acotado por un presidencialismo fuerte que entendía indispensable para evitar las guerras civiles y las divisiones internas que habían predominado en la historia reciente (Negretto, 2013: 139-149).

3 Los debates en torno a la reforma constitucional mexicana de 1996 que dispuso que la Cámara de Senadores se integraría por ciento veintiocho miembros, de los cuales en cada entidad territorial se elegirían tres (dos por la mayoría y otro por la primera minoría), mientras que los treinta y dos restantes se votarían a través del sistema de representación proporcional en una sola jurisdicción correspondiente al territorio nacional, constituyen un buen insumo para graficar la tensión entre el principio federal y la pluralidad democrática. A modo de ejemplo, puede consultarse el análisis socio-jurídico de Juan Francisco y Maribel Rivera Suárez (2014). 
Esta revista forma parte del acervo de la Biblioteca Jurídica Virtual del Instituto de Investigaciones Jurídicas de la UNAM

tramayoritaria de dicho cuerpo legislativo una explicación significativa de ese fracaso. Este trabajo se propone indagar con mayor profundidad acerca del peso que el esquema federal tuvo en esa votación.

En la próxima sección se analiza que los términos en los que se dio el debate en el Senado debilitan aquella línea argumental y echan luz sobre otras razones que fueron decisivas para el archivo de la iniciativa. A esos fines, además de recurrir a material periodístico, se recopila información de las actas de votación de ambas Cámaras, los textos de las Constituciones provinciales y los discursos de senadoras y senadores, sintetizada en los cuadros de elaboración propia que se incluyen en el mismo apartado.

Sobre esa base, se problematiza el énfasis puesto en el funcionamiento institucional que — según se aborda en la tercera sección - produce un desplazamiento del eje de la discusión pública obstaculizando la desarticulación de los discursos y la identificación de los actores detrás del sostenimiento de la criminalización del aborto.

Además, a partir del examen de documentos bibliográficos, notas de distintos medios, antecedentes normativos y otros jurisprudenciales, en la sección previa a las reflexiones finales se considera que el sobredimensionamiento de una responsabilidad negativa del federalismo tiene como efecto la minimización del potencial de esta forma de organización para lograr avances concretos en el camino hacia la interrupción legal del embarazo.

\section{EL TRATAMIENTO DE LA LEGALIZACIÓN DEL ABORTO EN EL SENADO}

El debate legislativo en torno a la interrupción voluntaria del embarazo se enmarca en el largo proceso de lucha por una agenda de género y ampliación de derechos, que han llevado adelante las organizaciones feministas y de la disidencia sexual en Argentina, con notables conquistas normativas en materia de salud sexual y reproductiva, anticoncepción quirúrgica, educación sexual integral, matrimonio igualitario e identidad de género. ${ }^{4}$ Como un hito decisivo de ese devenir, aparece la conformación

4 Véanse como ejemplos las Leyes 25.673 (Boletín Oficial del 22/11/2002), 26.130 (Boletín Oficial del 29/8/2006), 26.150 (Boletín Oficial del 26/10/2006), 26.618 (Boletín Oficial del 22/7/2010) y 26.743 (Boletín Oficial del 24/5/2012).

Cuestiones Constitucionales, Núm. 44, Enero-Junio 2021

ISSN: $2448-4881$ 
Esta revista forma parte del acervo de la Biblioteca Jurídica Virtual del Instituto de Investigaciones Jurídicas de la UNAM

de la Campaña Nacional por el Aborto Legal, Seguro y Gratuito al calor de los Encuentros Nacionales de Mujeres que, después de impulsar este proyecto de ley por más de una década, en 2018 lo presentó por séptima vez y obtuvo la aprobación de la Cámara de Diputados, favorecida por la confluencia de distintos factores que van desde la coyuntura política y los avances judiciales de años anteriores, hasta la enorme capacidad de movilización desarrollada por el activismo feminista contra la violencia de género bajo la consigna de "Ni una menos" y los paros de mujeres (Ruiz Tena y D'Alessandro, 2020: 12-23).

En ese contexto, el freno a la iniciativa de legalización del aborto que se produjo en la sesión del Senado del 8 y 9 de agosto de ese mismo año, es un hecho que juzgado superficialmente puede llevar a conclusiones engañosas sobre la incidencia del federalismo en el resultado. En las posiciones adoptadas por las y los representantes de las distintas jurisdicciones en ambas Cámaras, hay indicios que desdibujan la existencia de una supuesta relación causal entre las características de dicho marco institucional y los obstáculos que, en esa oportunidad, terminaron impidiendo la consagración normativa del derecho de las personas gestantes a decidir sobre sus cuerpos y acceder a prestaciones sanitarias que lo operativicen.

En los párrafos que siguen se esboza la dificultad de encuadrar el tratamiento que tuvo este proyecto en una visión que contrapone al progresismo porteño con el interior atrasado y presume una actitud reaccionaria de las senadoras y senadores ante los adelantos alcanzados en la Cámara de Diputados. Más adelante, se presentan datos que atenúan tanto el impacto del carácter igualitario de la representación territorial en la resolución adoptada por el Senado, como el compromiso de sus integrantes con los mandatos constitucionales locales y la defensa de las autonomías provinciales.

La imagen de la cámara alta como un ámbito de protección institucional de las elites regionales retrógradas frente al crecimiento poblacional, la heterogeneidad y la modernidad de las áreas metropolitanas (Gibson, 2004: 25), se atempera al considerar que dos de los tres representantes de la Ciudad Autónoma de Buenos Aires, que es el centro urbano más importante de la Argentina, se manifestaron en contra de la propuesta.

Por otro lado, la comparación del voto de las y los representantes de algunas provincias en el Senado y en la Cámara de Diputados, graficada en el cuadro 1, es útil para ilustrar que las posturas de quienes en principio 
Esta revista forma parte del acervo de la Biblioteca Jurídica Virtual del Instituto de Investigaciones Jurídicas de la UNAM

defienden los intereses locales no son necesariamente más conservadoras que las encarnadas por quienes, por definición, conforman la voz del pueblo. Córdoba es una provincia paradigmática porque sus tres senadores y senadoras acompañaron la legalización del aborto, pero doce de sus dieciocho diputados y diputadas votaron negativamente y uno se abstuvo. Algo similar sucedió entre las y los representantes de Chubut, Mendoza y Chaco que, en su mayoría, apoyaron la iniciativa en el Senado y la rechazaron en la Cámara de Diputados. Es un fenómeno que puede emparentarse con la "vigorización de la Cámara de Senadores" (Bazán, 2019: 1121) derivada de la mencionada reforma constitucional de 1994 que consagró la elección directa de sus miembros, acortó sus mandatos e incrementó a tres el número de bancas por provincia a fin de incorporar a las minorías.

De la misma manera, hay elementos que permiten relativizar el impacto de la sobre-representación de las provincias menos pobladas y la hipótesis que las asocia en bloque con concepciones fuertemente religiosas y tradicionalistas. 
Esta revista forma parte del acervo de la Biblioteca Jurídica Virtual del Instituto de Investigaciones Jurídicas de la UNAM http://www.juridicas.unam.mx

Cuadro 1. Resultados de la votación del proyecto de legalización del aborto en el Senado y la Cámara de Diputados, por provincia. Constituciones provinciales que reconocen el derecho a la vida desde la concepción.

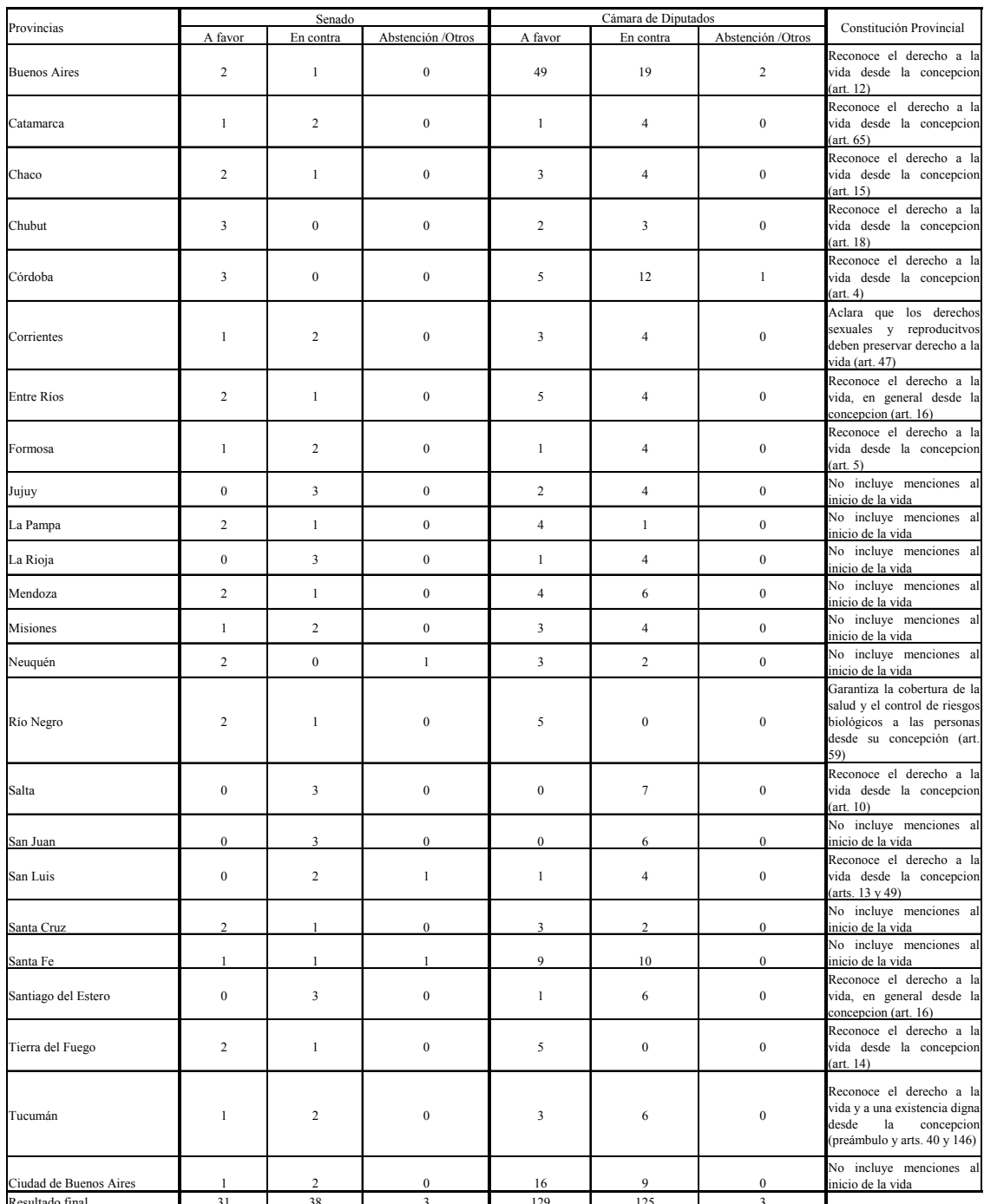

Fuentes: Elaboración propia en base al Acta de Votación $\mathrm{N}^{\circ} 1$ del Senado de la Nación, Sesión del 8/8/2018, Expte. CD 22/18 y Acta de Votación $\mathrm{N}^{\circ} 1$ de la Cámara de Diputados, Sesión del 14/6/18, Expte. 230-D-2018 y agregados. Relevamiento de Constituciones provinciales: http://www.infoleg.gob.ar/?page_id=45

Tomando las doce jurisdicciones que a la fecha del último censo nacional (Instituto Nacional de Estadísticas y Censos - INDEC, 2010: 65) tenían menos de setecientos mil habitantes se advierte, según el mismo Cuadro 1, que las senadoras y senadores de seis de ellas (Catamarca, Formosa, Jujuy, 
Esta revista forma parte del acervo de la Biblioteca Jurídica Virtual del Instituto de Investigaciones Jurídicas de la UNAM

La Rioja, San Juan y San Luis) aportaron quince votos por la negativa, dos por la afirmativa y una ausencia, mientras que las otras seis (Chubut, La Pampa, Neuquén, Río Negro, Santa Cruz y Tierra del Fuego) hicieron lo propio con trece votos a favor, cuatro en contra y una abstención.

En este punto y a modo de paréntesis, cabe destacar el rol concluyente que tuvo el diálogo del entonces gobernador de La Pampa, Carlos Verna, con los diputados y diputadas de esa provincia para conformar la mayoría que logró la media sanción en la Cámara de Diputados (Bullorini, 2018), contradiciendo las perspectivas críticas del federalismo que prejuzgan el accionar de las mandatarias y los mandatarios locales.

Volviendo al Senado, allí tampoco hubo una correspondencia exacta del voto de las y los representantes provinciales con la vigencia de textos constitucionales subnacionales que reconocen explícitamente el derecho a la vida a partir de la concepción. El relevamiento sintetizado en el Cuadro 1 muestra que son catorce las jurisdicciones cuyas Constituciones incorporan alguna cláusula de este tipo y que - sobre los cuarenta y dos representantes que ellas suman en total - veintiuno se opusieron a la legalización del aborto, pero veinte la avalaron restando trascendencia a la literalidad de tales preceptos y una senadora no participó de la votación. Esta fuente se toma como máxima expresión de las autonomías provinciales a los fines del análisis de la influencia del federalismo en la votación, sin perder de vista que en Argentina está vigente un extenso corpus jurídico que niega el carácter absoluto de ese interés para proteger la salud sexual y reproductiva, la integridad física y sicológica, la autonomía y la igualdad de las personas gestantes (Centro de Estudios Legales y Sociales, 2015).

Por último y como se visualiza en el Cuadro 2, la versión taquigráfica de aquella sesión del Senado deja ver que las referencias a cuestiones federales no ocuparon un lugar central en los discursos e inserciones que las senadoras y senadores realizaron durante la sesión plenaria en la que se resolvió el archivo del proyecto de legalización del aborto.

Esa jornada, participaron sesenta y seis senadoras y senadores. De los treinta y cinco que se expresaron para impugnar la iniciativa, dieciocho apelaron a fundamentos de tinte constitucional, político, religioso y científico totalmente ajenos al federalismo. Solo doce hicieron alguna mención vinculada a que la aprobación del proyecto implicaba un avasallamiento federal de las autonomías provinciales. 
Esta revista forma parte del acervo de la Biblioteca Jurídica Virtual del Instituto de Investigaciones Jurídicas de la UNAM

Cuadro 2. Senadoras y senadores que hicieron uso de la palabra y/o insertaron discursos en la sesión del 8 y 9 de agosto, según su voto y orden en la versión taquigráfica. Utilización de referencias al federalismo. El argumento del avasallamiento federal sobre competencias provinciales.

En contra de la legalización del aborto o abstenciones

Presencia del argumento del avasallamiento federal

Presencia del argumento del avasallamiento federal
\begin{tabular}{|l|c|c|}
\hline Nombre & Provincia & Pág. VT \\
\hline Fiad, Mario R. & Jujuy & 9 \\
\hline Mera, Dalmacio E. & Catamarca & 21 \\
\hline Solari Quintana, Magdalena & Misiones & 45 y 206 \\
\hline López Valverde, Cristina & San Juan & 77 \\
\hline De Angeli, Alfredo L. & Entre Ríos & 82 y 249 \\
\hline Varela, Marta & CABA & 121 \\
\hline Poggi, Claudio J. & San Luis & 132 \\
\hline Crexell, Carmen L. & Neuquén & 134 \\
\hline Mayans, José M. & Formosa & 161 \\
\hline Closs, Maurice F. & Misiones & 168 \\
\hline Elías de Peréz, Silvia B. & Tucumán & 198 \\
\hline Reutemann, Carlos & Santa Fe & 251 \\
\hline
\end{tabular}

Mención a la Constitución Provincial

\begin{tabular}{|l|c|c|}
\hline Nombre & Provincia & Pág. VT \\
\hline González, María T. & Formosa & 53 \\
\hline Boyadjian, Miriam R. & Tierra del Fuego & 57 \\
\hline Blas, Inés I. & Catamarca & 92 y 247 \\
\hline Rodríguez Saá, Adolfo & San Luis & 180 \\
\hline Menem, Carlos S. & La Rioja & 253 \\
\hline
\end{tabular}

Ausencia de referencias al federalismo

Ausencia de referencias al federalismo
\begin{tabular}{|l|c|c|}
\hline Nombre & Provincia & Pág. VT \\
\hline Brizuela y Doria, Olga I. & La Rioja & 29 y 242 \\
\hline Bulrrich, Esteban & Buenos Aires & 36 \\
\hline Urtubey, Rodolfo J. & Salta & 39 \\
\hline Iturrez de Capellini, Ada R. & Sgo. del Estero & 49 \\
\hline Cobos, Julio C. & Mendoza & 64 \\
\hline Montenegro, Gerardo A. & Sgo. del Estero & 72 \\
\hline Tapia, María B. & Santa Cruz & 80 \\
\hline Braillard Poccard, Néstor & Corrientes & 87 \\
\hline Basualdo, Roberto G. & San Juan & 102 y 206 \\
\hline Giacoppo, Silvia del R. & Jujuy & 111 y 256 \\
\hline Garcia Larraburu, Silvia M. & Rio Negro & 127 y 258 \\
\hline Perotti, Omar A. & Santa Fe & 129 y 320 \\
\hline Romero, Juan C. & Salta & 139 \\
\hline Uñac, José R. & San Juan & 145 \\
\hline Pinedo, Federico & CABA & 153 \\
\hline Rozas, Angel & Chaco & 165 \\
\hline Fiore Viñuates, María C. & Salta & 182 \\
\hline Snopek, Guillermo E. & Jujuy & 241 \\
\hline
\end{tabular}

Fuentes: Elaboración propia en base a la versión taquigráfica del Senado de la Nación Argentina. Periodo 136, $10^{\circ}$ Reunión, 5 ta. Sesión Especial (8 y 9 de agosto de 2018)

Puntualmente, lo acusaron de responder a un sesgo antifederal o unitario, sugiriendo una eventual vulneración del principio de reserva de las provincias sobre las competencias no delegadas y/o sosteniendo que se inmiscuía en atribuciones concurrentes del área de salud que el Congreso Nacional debía limitarse a regular a través de leyes de adhesión y no mediante normas de orden público como la propuesta. Asimismo, realizaron declaraciones contrarias a la pretensión de imponer programas con prestaciones y obligaciones de financiamiento sin medir su impacto en los sistemas sanitarios provinciales ni su capacidad presupuestaria.

Hubo otras cinco senadoras y senadores que para justificar el voto remitieron a los textos constitucionales de sus distritos, aunque ubicándolos en consonancia con una errada exégesis del marco jurídico nacional, restricti-

Cuestiones Constitucionales, Núm. 44, Enero-Junio 2021

ISSN: $2448-4881$ 
Esta revista forma parte del acervo de la Biblioteca Jurídica Virtual del Instituto de Investigaciones Jurídicas de la UNAM

va del aborto. En estos casos igual que en los anteriores, las intervenciones atinentes al federalismo fueron secundarias.

Ese tópico también estuvo prácticamente ausente entre las enunciaciones de las y los treinta y un representantes que dieron su visto bueno a la propuesta. Una única senadora refutó las objeciones enumeradas, haciendo hincapié en las responsabilidades asumidas por el Estado federal en materia de derechos humanos frente a los organismos internacionales.

Lo expuesto en esta sección no tiene como objetivo idealizar al Senado ni pasar por alto la tensión entre su existencia y la regla de la mayoría o las dificultades que atraviesan su funcionamiento, sino simplemente señalar que la lógica de esa institución propia del federalismo no fue determinante en el debate de la legalización del aborto y que sobreactuar su gravitación lleva a perder de vista los ejes discursivos a partir de los cuales se articuló el rechazo.

\section{LAS RAZONES Y ACTORES DETRÁS \\ DE LA CRIMINALIZACIÓN DEL ABORTO}

Conforme resulta corroborado por la misma versión taquigráfica, las participaciones de las senadoras y senadores que votaron en contra de la iniciativa coincidieron en resaltar como eje central de su argumentación, que la vida humana comienza desde la concepción y en asimilar al embrión o al feto con una persona: el niño por nacer, en ocasiones valiéndose de pruebas científicas aparentemente neutrales, a través de las cuales se busca definirlo como un ser separado e independiente de quien lleva adelante la gestación.

En base a ese punto de partida enunciado como una verdad natural e incontrovertible, esgrimieron que la vida a partir de ese momento se constituye en un derecho absoluto que no admite límites, que es fuente de los demás derechos y está amparado por el marco jurídico nacional e internacional. En ese sentido, plantearon una lectura parcializada de distintas normas que reconocen derechos antes y después del nacimiento como el artículo 75 inciso 23 de la Constitución Nacional, los artículos 19 al 21 del Código Civil y la Convención Americana de Derechos Humanos, en contra de antecedentes como "F.A.L." de la Corte Suprema de Justicia de la Nación (2012, considerandos 8 a 13) y "Artavia Murillo" de la Corte Interamericana de Derechos Humanos (2012: 77-87). También se ampara-

Cuestiones Constitucionales, Núm. 44, Enero-Junio 2021

ISSN: 2448-4881 
Esta revista forma parte del acervo de la Biblioteca Jurídica Virtual del Instituto de Investigaciones Jurídicas de la UNAM

ron en una interpretación antojadiza de la Convención sobre los Derechos del Niño y la declaración efectuada por el Estado argentino respecto a ese tratado, ignorando observaciones en contrario del Comité de los Derechos del Niño (2018: 7).

Recurrieron igualmente a defensas cerradas de la libertad religiosa de las y los profesionales de la salud como sustento de la negativa a la práctica del aborto y reivindicaron el ejercicio de la objeción de conciencia institucional por parte de los establecimientos sanitarios con vínculos confesionales.

En sus alocuciones no dejaron espacio a la autonomía de las personas gestantes, reduciendo el derecho a decidir sobre sus propios cuerpos a un simple deseo que no merece protección o a una elección realizada sin el consentimiento del padre y en contra de los instintos más profundos de la mujer. Entendieron la maternidad como un mandato biológico y un medio de realización sobre todo para aquellas mujeres pertenecientes a los sectores más vulnerables. Algunos discursos subrayaron los efectos físicos y sicológicos que la interrupción de un embarazo provocaría en la mujer e incluso hablaron de trastornos mentales que posteriormente impactarían en sus vidas personales y familiares.

También estuvieron quienes se aprovecharon de la falta de cifras oficiales propia de la ilegalidad a fin de negar la magnitud de los abortos clandestinos y acudieron a estadísticas para restarles importancia como causa de muerte entre la población femenina.

Entremezcladas con otras justificaciones de índole eminentemente religiosa o atinentes a la conveniencia política, surgieron todas las anteriores de carácter secular que muchas veces usan el lenguaje de los derechos humanos, se asientan en interpretaciones constitucionales y reseñan datos empíricos, dejando al descubierto una estrategia novedosa y común con la desplegada por los sectores que se oponen a la legalización del aborto en otros países de la región (Malca, 2018: 353-358).

Detrás de la misma, se encuentra un vasto movimiento social, religioso y conservador que excede a la Iglesia Católica y se revela a través de múltiples organizaciones que se postulan a sí mismas como guardianas de la vida, la familia y otros valores tradicionales. Son expresiones que cruzan a la sociedad argentina sin límites territoriales, más allá de la innegable raigambre que tienen en algunas zonas del país, en particular, el noroeste. 
Esta revista forma parte del acervo de la Biblioteca Jurídica Virtual del Instituto de Investigaciones Jurídicas de la UNAM

Tienen llegada directa a las elites políticas y cuentan con representantes en los poderes y organismos del Estado.

Cuando a contramano de muchos pronósticos, el proyecto de legalización del aborto pasó la Cámara de Diputados, la fuerza política y económica de este movimiento se hizo sentir en los medios de comunicación, las redes sociales y las calles (Ruiz Tena y D'Alessandro, 2020: 49). Distintos discursos dieron cuenta de la percepción de un cambio en el tono de la discusión que incorporó escraches y amenazas contra quienes dejaban entrever un enfoque favorable a la interrupción legal del embarazo. La ex vicepresidenta de la Nación, Gabriela Michetti, se autoerigió en vocera de ese movimiento y condicionó el tratamiento de la iniciativa. La presión ejercida también coadyuvó a que Mauricio Macri, quien desde la Presidencia de la Nación meses antes había dado vía libre al debate parlamentario, no tomara una posición clara y que tanto la gobernadora - ahora mandato cumplido - de la Provincia de Buenos Aires, María Eugenia Vidal como el jefe de gobierno porteño, Horacio Rodríguez Larreta, dejaran ver su rechazo (Debesa, 2018; Infobae, 2018).

La cosificación de la mujer defendida por este movimiento como contrapartida de la humanización del feto, también tiene raíces profundas en un orden patriarcal que todavía recorta su condición de ciudadanía y la confina a un papel de reproductora de la especie, la fuerza de trabajo y el orden social que debe ejercer a costa de cualquier sacrificio. Se entronca en una cultura de la desigualdad que trasciende al federalismo. El intento de ocultarla detrás de diferencias geográficas conlleva a dejar de problematizar que la mitad de las senadoras, incluida aquella que estaba a cargo de la Banca de la Mujer, votaron en contra de la legalización del aborto. El riesgo es menospreciar uno de los grandes desafíos que enfrenta el movimiento feminista: concientizar a las mujeres, en general y en particular a las que acceden a lugares de representación, acerca del contexto machista que modela sus opiniones y trayectorias políticas.

Tomar debida noción de todos estos argumentos y explorar como se relacionan entre sí brinda mejores posibilidades de desarticularlos y confrontarlos con nuevas respuestas, contribuye a visibilizar a los actores que los sostienen, detectar sus modus operandi y evaluar alternativas para contrarrestar su poder de influencia sobre el público en general y los agentes políticos, judiciales y sanitarios que tienen competencias para hacer efectivo el derecho al aborto legal (Niño Contreras y Rincón Escalante, 2018: 380). 
Esta revista forma parte del acervo de la Biblioteca Jurídica Virtual del Instituto de Investigaciones Jurídicas de la UNAM

\section{APORTES DEL FEDERALISMO AL DEBATE DEL ABORTO LEGAL}

Además de correr el foco de los argumentos medulares y los actores detrás del freno al proyecto del movimiento feminista, centrarse exclusivamente en el resultado final de la votación en el Senado, también es contraproducente porque desmerece los aportes que el federalismo está en condiciones de hacer para lograr avances en pos de la legalización del aborto. En esta sección se especifican ciertos caracteres de ese modelo de organización que sirven a dicho objetivo y algunos casos empíricos en Argentina y otros países del continente.

Las jurisdicciones territoriales pueden actuar como laboratorios de experimentación para implementar programas, prestar servicios y aprobar normas (Ribstein y Kobayashi, 2006: 5), sobre todo con relación a cuestiones cultural e ideológicamente controvertidas como el aborto, frente a las que resulta complejo arribar a decisiones políticas uniformes en el orden nacional. En el fallo "Chiara Díaz", a través del voto de los jueces Lorenzetti y Zaffaroni, la Corte Suprema de Justicia de la Nación (2006, considerando 9) ha visualizado a los desarrollos provinciales y la pluralidad de sus ensayos como una rica fuente para el progreso de las instituciones nacionales de Argentina.

Las conquistas locales en torno a la interrupción legal del embarazo son útiles para instalar el tema en las agendas públicas, indicar caminos diferentes, ampliar paulatinamente las bases de consenso social y destrabar soluciones de alcance federal.

Es lo que ocurrió en México cuando, en 2007, el Distrito Federal reformó su Código Penal para descriminalizar el aborto por voluntad de las personas gestantes durante el primer trimestre de embarazo y proporcionar ese servicio gratuito en hospitales públicos. En una sociedad con predominio católico y donde la Iglesia despliega un fuerte rol político (Lamas, 2009), ese antecedente derivó en un pronunciamiento histórico de la Suprema Corte de Justicia de ese país que, un año más tarde, rechazó las impugnaciones efectuadas por el ombudsman federal y el procurador general de la República contra ese marco normativo. Después de recibir numerosos amicus curiae y celebrar audiencias públicas, el máximo tribunal definió a la vida prenatal como un bien jurídico protegido, pero lo puso en relación con derechos como la libertad y la autonomía reproductiva de las 
Esta revista forma parte del acervo de la Biblioteca Jurídica Virtual del Instituto de Investigaciones Jurídicas de la UNAM

mujeres, la igualdad y la problemática de salud pública que constituye la clandestinidad del aborto, para resolver que no existía un mandato constitucional explícito a favor de su penalización (Beltrán y Puga, 2018: 67).

Aunque en el corto plazo, ese soporte jurídico-institucional provocó la reacción de grupos ultraconservadores que fomentaron la adopción de normas dirigidas a restringir la práctica del aborto por parte de otras legislaturas estaduales (Albarrán de Alba, 2009), también fue funcional a la promoción de reformas similares a la del Distrito Federal mexicano. La primera en concretarse tuvo lugar en Oaxaca que, hacia fines de 2019, se convirtió en el segundo distrito en autorizar la interrupción voluntaria del embarazo hasta las doce semanas, aun cuando no alcanzó la mayoría agravada exigida para modificar el texto constitucional local que garantiza el derecho a la vida desde la fecundación. Desde el activismo, se ha considerado a esta aprobación como una "señal importante para el resto del país", proveniente de una de las jurisdicciones más pobres y con mayor número de comunidades indígenas (Reina, 2019).

En Argentina, donde la competencia constitucional de sancionar los códigos de fondo recae sobre el Congreso Nacional, igual existe la oportunidad de aprovechar la mayor efectividad de las movilizaciones que existe en los niveles subnacionales (Powell, 2001: 245) y explorar alianzas con gobiernos locales que son sensibles a la protección de los derechos de las mujeres y han llevado adelante políticas tendientes a garantizar la realización de abortos no punibles y ampliar los márgenes de las causales legalmente aceptadas, en consonancia con el mencionado fallo "F.A.L." (Corte Suprema de Justicia de la Nación, 2012) que incluyó a los supuestos de violación en general (considerando 18), sin exigencia de denuncia penal o autorización judicial de ningún tipo (considerando 27), encargando a las autoridades nacionales y locales la elaboración de protocolos hospitalarios adecuados (considerando 29).

Modelos como el llevado adelante por el Ministerio de Salud de la Provincia de Santa Fe (2012) que implementó un protocolo de abortos no punibles e impulsó la producción de misoprostol para ese mismo fin a través del Laboratorio Industrial Farmacéutico Sociedad del Estado, están a disposición de las organizaciones feministas como parámetro para acreditar buenos resultados en materia de no judicialización, calidad de atención y erradicación de las muertes por abortos inseguros, derribar prejuicios y generar un diálogo ciudadano que facilte a las mujeres tomar conciencia de sus propios derechos (Azrak, 2019: 42). En definitiva, se trata de observar 
Esta revista forma parte del acervo de la Biblioteca Jurídica Virtual del Instituto de Investigaciones Jurídicas de la UNAM

cómo otros distritos han intentado resolver problemas que son comunes y adoptar las prácticas exitosas acomodándolas a las particularidades locales. Es una forma de federalismo horizontal (Tarr, 2001: 93) que, en el mediano y largo plazo, promueve uniformidades más extensas.

Hacia fines de 2019, esa política de Santa Fe cobró nueva notoriedad y fue reinvindicada en apoyo a la resolución adoptada por la ex Secretaría de Gobierno de Salud de la Nación (2019) para promover el derecho a acceder a la interrupción legal del embarazo en todo el territorio nacional, y en contraste con la decisión de derogarla de quien ocupaba la Presidencia de la Nación (2019). Este hecho expone cómo las experiencias provinciales son utilizadas para poner en evidencia las fallas y las carencias de las políticas nacionales, cubrir los vacios protectorios y presionar por cambios en ese nivel, además de establecer contactos y trabajar en red con otras organizaciones sociales (Powell, 2001: 275).

Sobre este punto, es válida la referencia a San Francisco que, en 1998, incorporó a su legislación local la Convención sobre la Eliminación de Todas las Formas de Discriminación contra la Mujer, produciendo efectos de gran valor simbólico (Powell, 2001: 277). La repercusión que la medida tuvo en otras ciudades y condados de los Estados Unidos de América, a pesar de la oposición de los sectores autodenominados "pro-vida", fue el puntapié inicial de la campaña "Cities for CEDAW", lanzanda en el 2013 con la mirada puesta en "hacer que el mundo sea local" mediante la aprobación de leyes que, en ese orden, inserten los principios internacionales de protección de los derechos de las mujeres y las niñas, sin esperar al gobierno federal.

Ante la ausencia de una administración central comprometida con la igualdad de género, que promueve retrocesos en este área, las esferas locales también se instituyen como espacios de denuncia y resistencia.

Como ejemplo, es oportuno mencionar a Estados subnacionales como Nueva York, California, Oregón e Illinois que continuan defendiendo y asegurando la práctica del aborto en los términos que la Corte Suprema de ese mismo país estableció en "Roe vs Wade" (1973, considerando XI). Esto a pesar de la avanzada de los sectores fundamentalistas religiosos agitados por la cultura misógina y contraria a la libertad reproductiva promovida por la administración de Trump quien, desde su llegada a la Casa Blanca, impulsó el nombramiento de magistrados contrarios al derecho al aborto y medidas para impedir que cualquier recurso público se destine a financiar organizaciones nacionales o extranjeras que apoyen o participen 
Esta revista forma parte del acervo de la Biblioteca Jurídica Virtual del Instituto de Investigaciones Jurídicas de la UNAM

en servicios de planificación familiar y programas de interrupción voluntaria del embarazo (Vicente y Otón Oliveri, 2018: 424). Es importante seguir la situación en dichos Estados subnacionales, en especial si aquellos donde el conservadurismo es más fuerte, como Alabama, Georgia, Missouri, Arkansas, Kentuky, Ohio y Utah, logran el aval del máximo tribunal en su nueva composición, a las leyes locales que obturan el acceso al aborto, sancionadas en ese contexto y hasta ahora bloqueadas por jueces federales.

Las provincias tienen la opción de retacear la aplicación de las politicas públicas nacionales en el territorio e influir de esa manera en su formulación. Esta táctica a la que recurren comúnmente los actores conservadores para impedir la aplicación de leyes que amplían derechos, puede ser un arma del movimiento feminista para repeler programas regresivos. En Argentina, tiene el sustento de la Corte Suprema de Justicia de la Nación (2015, considerando 25) que, a través del fallo "Nobleza Piccardo", entendió que el contenido de las normas nacionales no limita las potestades legislativas provinciales cuando son ejercidas para garantizar el derecho a la salud y tienen como guía los estándares internacionales.

Dicha atribución de los Estados subnacionales suele dar lugar a diferencias relevantes entre los marcos normativos protectorios que operan en las distintas jurisdicciones. Para comienzos de 2019, en Argentina había once provincias que adherían al protocolo de aborto no punible elaborado por autoridades nacionales, cinco que contaban con uno propio más amplio o más restrictivo y siete que carecían de uno (Economía Femini(s)ta, 2019).

Distintas autoras y autores identifican a esa peculiaridad de la estructura federal como causa de desigualdades geográficas, atento el impacto que tiene en la forma en que derechos y recursos se distribuyen entre las jurisdicciones (Smulovitz, 2015, p. 156). No obstante, aquí se sostiene que las diferencias territoriales no son exclusivas del federalismo y que los diseños institucionales consiguen exacerbarlas o minimizarlas, pero difícilmente revertirlas si no apuntan contra los múltiples factores económicos, sociales, culturales y políticos que las producen.

En Uruguay, un país unitario donde el aborto se legalizó en octubre de $2012,{ }^{5}$ el acceso a su práctica se ve obstaculizado por el ejercicio abusivo de la objeción de conciencia que también es geográficamente dispar. En los departamentos del Litoral los porcentajes de objetores u objetoras superan el sesenta por ciento $(60 \%)$ y hay localidades donde ascienden

5 Véase la Ley 18.987 (Diario Oficial del 30 de octubre de 2012, núm. 28.585).

Cuestiones Constitucionales, Núm. 44, Enero-Junio 2021

ISSN: 2448-4881 
Esta revista forma parte del acervo de la Biblioteca Jurídica Virtual del Instituto de Investigaciones Jurídicas de la UNAM

al cien por ciento (100\%), forzando el traslado de las personas gestantes que deciden la interrupción de los embarazos (Mujer y Salud en UruguayMySU, 2017, p. 48). Algo similar pasa en Chile que en 2017 despenalizó el aborto por tres causales, ${ }^{6}$ donde los hospitales públicos de determinadas regiones del país concentran a las y los profesionales objetores de conciencia (Corporación Humanas, 2018: 16).

Con esto no se intenta negar la problemática de la coexistencia de distintos estándares de protección legal dentro de un mismo Estado nacional, sino simplemente demostrar que las disparidades territoriales también existen en países con otras formas de organización y que el federalismo, si bien no las evita, logra visibilizarlas como conflicto y puede brindar mecanismos para solucionarlo (Powell, 2001: 250).

En primer lugar, el esquema federal conlleva a un sistema de doble seguridad para los derechos (Madison, Hamilton y Jay, 2001: 221) que ofrece a la ciudadanía la oportunidad de reclamar ante dos niveles judiciales distintos, viendo incrementadas sus chances de obtener alguna respuesta estatal.

Con relación a la interrupción legal del embarazo, en Argentina hay antecedentes en los que la protección local fue negada, como el controvertido fallo del Juzgado de Paso de los Libres (2019) que autorizó una adopción pre-natal en la Provincia de Corrientes, pero también hay otros en los que resultó suficiente o fue convalidada por la justicia federal como la sentencia del Tribunal Superior de Córdoba (2019) que rechazó el recurso de una organización conservadora y avaló el protocolo de aborto no punible elaborado por esa provincia siete años antes o el ya citado caso F.A.L.

En segundo lugar y desde una faceta dialógica que alienta el intercambio de información, la coordinación, la negociación y el aprendizaje mutuo entre las jurisdicciones (Powell, 2001: 249-254), el federalismo es susceptible de favorecer un acceso equitativo a la práctica de abortos no punibles y la construcción de consensos en torno a la legalización de la interrupción voluntaria del embarazo.

Siguiendo esa orientación teórica, es factible trazar algunas líneas de acción para avanzar en esa dirección. Aunque hacerlo con detalle excede el formato de este trabajo, entre ellas pueden mencionarse: a) la producción de información estadística oficial y el mapeo de la situación de los derechos de las mujeres y el aborto en cada jurisdicción; b) la generación

\footnotetext{
6 Véase la Ley 21.030 (Diario Oficial del 23 de septiembre de 2017, núm. 41.866).
} 
Esta revista forma parte del acervo de la Biblioteca Jurídica Virtual del Instituto de Investigaciones Jurídicas de la UNAM

y/o el fortalecimiento de ámbitos institucionales — como en Argentina son el Consejo Federal de Salud o los espacios interjurisdiccionales convocados desde el Ministerio de las Mujeres, Géneros y Diversidad - donde las provincias entre sí y con el Estado federal compartan experiencias, lleguen a diagnósticos comunes y acuerden políticas públicas; c) la transferencia de fondos nacionales con asignación específica al financiamiento de las políticas acordadas (Azrak, 2019: 53); d) el fomento de la participación de las organizaciones sociales locales en el control y seguimiento de su implementación; y e) la interpretación de la ley de interrupción voluntaria del embarazo a la luz del artículo 75 inciso 23 de ese país, como norma de pisos mínimos en materia de salud pública y medida de acción positiva destinada a garantizar la igualdad real de oportunidades (Clérico, 2010: 98).

Un sistema que puede tenerse en cuenta es el de Canadá donde el derecho al aborto está comprendido dentro del "Health Act", la normativa federal que establece criterios y condiciones generales para asegurar la provisión de los servicios de salud pública, cuya regulación compete a las provincias (Petrone y Ramallo, 2018: 3).

\section{REFLEXIONES FINALES}

El repaso de los pormenores del debate que el proyecto de aborto legal, seguro y gratuito tuvo en el Senado de la Nación Argentina, realizado al comienzo de este trabajo, contrarresta el peso que el principio de representación territorial propio de ese cuerpo tuvo en el resultado de la votación contraria a su aprobación en 2018.

Las razones políticas, religiosas e ideológicas que primaron en el transcurso de aquella sesión trascienden las fronteras territoriales y son enarboladas por actores conservadores que — como quedó de manifiesto en la tercera sección - cuentan con llegada directa y una fuerte capacidad de influencia sobre el poder político, judicial y comunicacional.

Desentrañar sus argumentos y comprender cómo actúan es fundamental para elaborar líneas discursivas más efectivas en defensa del acceso a la interrupción voluntaria del embarazo, persuadir a actores estratégicos y articular nuevas tácticas encaminadas a ampliar los consensos para su legalización, soportar el recrudecimiento de las contra-movilizaciones y 
Esta revista forma parte del acervo de la Biblioteca Jurídica Virtual del Instituto de Investigaciones Jurídicas de la UNAM

los embates judiciales que, sin dudas, se profundizarán en caso de lograr ese objetivo.

Los aspectos del federalismo enfatizados en la cuarta sección admiten dar una respuesta afirmativa al interrogante que se propone como disparador: existe un margen sustancial para que el movimiento feminista encuentre un aliado en esa forma de organización.

Incrementar la presencia en los ámbitos locales y fortalecer los lazos con sus organizaciones resulta decisivo para que las denuncias de vulneración de derechos tengan más impacto, hacer un seguimiento de casos individuales y promover litigios estructurales, relevar buenas experiencias, darlas a conocer y confrontarlas con incumplimientos en el orden nacional.

El diálogo, la negociación y la coordinación son para un Estado federal herramientas fundamentales para superar los impedimentos que restringen el acceso a la interrupción legal del embarazo en el orden local y equiparar derechos en un sentido progresivo.

En Argentina, la reciente elección de un presidente de la Nación de buen entendimiento con gobernadores y gobernadoras provinciales, su encuentro con referentes feministas y el anuncio público de su compromiso con la legalización del aborto, hace presumir que existen mayores posibilidades para destrabar tales mecanismos y lograr avances en esa lucha del movimiento feminista. ${ }^{?}$

\section{FUENTES CONSULTADAS}

Albarrán De Alba, G. (2009, 7 de junio). Después del D.F. la reacción. Página 12. Sociedad. Disponible en: https://www.pagina12.com. ar/diario/sociedad/3-126225-2009-06-07.html.

AlBerdi, J. B. (2017). Bases y puntos de partida para la organización política de la República Argentina. Buenos Aires: Biblioteca del Congreso de la Nación.

7 Con posterioridad a la elaboración y presentación de este trabajo, el Congreso argentino sancionó la Ley 27.610 (Boletín Oficial del 15 de enero de 2021) que posibilita el acceso a la interrupción voluntaria del embarazo y garantiza el derecho a la atención postaborto, en base a un proyecto de ley remitido por el presidente de la Nación, Alberto Fernández; hecho que refuerza la idea expuesta en este párrafo. 
Esta revista forma parte del acervo de la Biblioteca Jurídica Virtual del Instituto de Investigaciones Jurídicas de la UNAM

AZRAK, D. (2019). Una teoría federal para la educación sexual integral. Manuscrito inédito.

BAZÁN, V. (2019). El federalismo argentino en foco: un recorrido crítico. En Gargarella, R. y Guidi, S. (dirs.), Constitución de la Nación Argentina Comentada. Buenos Aires: La Ley.

BELTRÁN Y PUGA, A. (2018). La jurisprudencia constitucional sobre el aborto en México. En Bergallo, P. y Jaramillo Sierra, I. C. (comps.). El aborto en América Latina. Estrategias jurídicas para luchar por su legalización y enfrentar las resistencias conservadoras. Buenos Aires: Siglo XXI.

Bullorini, J. (2018, 14 de junio). Despenalización del aborto. Trastienda de la decisión que dio vuelta el resultado. Clarín Digital. Política, disponible en: https://www.clarin.com/politica/trastienda-decision-diovuelta-resultado-gobernador-carlos-verna-pidio-votar-favor_O_HJKWm $7 g$-Q.html.

Centro de Estudios Legales y Sociales (2015). Aportes del CELS a los debates legislativos sobre los derechos sexuales y reproductivos, disponible en: https://www.cels.org.ar/web/wp-content/uploads/2016/10/ Derechos-sexuales-y-reproductivos.pdf.

CLÉRICO, L. (2010). ¿El argumento del federalismo vs. el argumento de igualdad? El derecho a la salud de las personas con discapacidad. Revista Jurídica de Palermo.

Comité de los Derechos del Niño (2018). Observaciones finales sobre los informes periódicos quinto y sexto combinados de la Argentina. Disponible en: https://amnistia.org.ar/esiya/observaciones-finales-sobrelos-informes-periodicos-quinto-y-sexto-combinados-de-la-argentinadel-comite-de-los-derechos-del-nino.

Corporación Humanas (2018). Realidad del aborto en Chile. Revisión estadística. Centro Regional de Derechos Humanos y Justicia de Género. Disponible en: http://www.humanas.cl/wp-content/uploads/2018/08/ HUMANAS-Realidad-del-aborto-en-Chile-20-08-2018.pdf.

Corte Interamericana de Derechos Humanos (2012, 28 de noviembre). Artavia Murillo y otros ("Fecundación In Vitro") vs. Costa Rica. Disponible en: https://www.corteidh.or.cr/docs/casos/articulos/seriec_257_esp.pdf.

DAHL, R. (1983). Federalism and the Democratic Process. Nomos, 25, $95-$ 108. 
Esta revista forma parte del acervo de la Biblioteca Jurídica Virtual del Instituto de Investigaciones Jurídicas de la UNAM

Debesa, F. (2018, 9 de julio). En el Tedeum, María Eugenia Vidal se mostró con el pañuelo celeste de la campaña «por las dos vidas» contra el aborto. Clarín Digital. Política. Disponible en: https://www.clarin. com/politica/maria-eugenia-vidal-mostro-panuelo-celeste-campanavidas-aborto_0_r1-kHIZQ7.html.

Economía Femini(s)ta (2019, 8 de marzo). Mapa de Adhesión al Protocolo de Aborto No Punible en la Argentina. Disponible en: https://economi afeminita.com/mapa-de-adhesion-al-protocolo-de-aborto-no-punibleen-la-argentina/.

FERNÁNDEZ SEGAdO, F. (2002). Reflexiones críticas en torno al federalismo en América Latina. En Serna de la GarZA, J. M. (comp.). Federalismo y regionalismo. Memoria del VII Congreso Iberoamericano de Derecho Constitucional. México, UNAM, Instituto de Investigaciones Jurídicas. Disponible en: https://archivos.juridicas.unam.mx/www/bjv/ libros/1/348/7.pdf.

GiBSON, E. (2004). Federalism and Democracy: Theorical Connections and Cautionary Insights. En GiBSON, E. (ed.), Federalism and Democracy in Latin America, 1-28. Baltimore: The Johns Hopkins University Press.

GIBSON, E. y Falleti, T. (2004). Unity by the Stick. Regional conflicts and the origins of Argentine Federalism. En GIBSON, E. (ed.), Federalism and Democracy in Latin America, 226-254. Baltimore: The Johns Hopkins University Press.

Infobae (2018, 11 de julio). Fuerte gesto de Horacio Rodríguez Larreta a la Iglesia en medio de la discusión por el aborto. Infobae Digital, disponible en: https://www.infobae.com/circulo-rojo/2018/07/11/abortoel-gesto-de-rodriguez-larreta-y-su-mujer-a-la-iglesia/.

Instituto Nacional de Estadísticas y Censos - INDEC (2010). Censo Nacional de Población, Hogares y Vivienda, Resultados definitivos, núm. 2, t. 1, disponible en: https://www.indec.gob.ar/ftp/cuadros/poblacion/ censo2010_tomo1.pdf.

Lamas, M. (2009). La despenalización del aborto en México. Nueva Sociedad, NUSO 220, marzo-abril, disponible en: https://nuso.org/articulo/la-despenalizacion-del-aborto-en-mexico/.

MAdison, J. et al., (2001). El Federalista. 2a. ed. en español. México: Fondo de la Cultura Económica. 
Esta revista forma parte del acervo de la Biblioteca Jurídica Virtual del Instituto de Investigaciones Jurídicas de la UNAM

MALCA, C. (2018). "Movimiento trasnacional contra el derecho al aborto en América Latina", en Bergallo, P. et al. (comps.), El aborto en América Latina. Estrategias jurídicas para luchar por su legalización y enfrentar las resistencias conservadoras. Buenos Aires: Siglo XXI.

Ministerio de Salud de la Provincia de Santa Fe (2012, 17 de abril) Resolución 612. Adhesión a la Guía Técnica para la Atención de Abortos No Punibles, disponible en: http://test.e-legis-ar.msal.gov.ar/leisref/public/ showAct.php?id=20358.

Mujer y Salud en Uruguay - MySU (2017). Los servicios de salud sexual y reproductiva y aborto legal. Monitoreo 2013-2017. Observatorio Nacional en Género y Salud Sexual-Reproductiva en Uruguay, disponible en: https://issuu.com/mujerysaludenuruguay/docs/informe_ observatorio_2017_10de19_we.

Negretto, G. (2013). Los orígenes del presidencialismo en América Latina: un estudio sobre el proceso constituyente argentino (1853-1860). Revista Latinoamericana de Política Comparada, 7, julio, disponible en: https://repositorio.flacsoandes.edu.ec/bitstream/10469/14230/1/ REXTN-RLPC07-06-Negretto.pdf.

NiÑo CONTRERAS, M. I. y RinCón EsCAlAnTE, J. C. (2018). Radiografía de los argumentos consevadores contra el aborto en Colombia. Sugerencias para un movimiento pro liberalización. En BERGALLO, P. et all. (comps.), El aborto en América Latina. Estrategias jurídicas para luchas por su legalización y enfrentar las resistencias conservadoras. Buenos Aires: Siglo XXI.

Petrone, C. y Ramallo, M. (2018). Debate sobre el aborto: El Modelo de despenalización en Canadá. Centro de Derechos Humanos de la Universidad de Buenos Aires, disponible en: http://www.derecho.uba. ar/institucional/centro-derechos-humanos/pdf/2018_canada.pdf.

Powell, C. (2001). Dialogic Federalism: Constitutional Possibilities for Incorporation of Human Rights Law in the United States. 150 U. Pa. L. Rev., 245-295.

REINA, E. (2019, 26 de septiembre). México da un gran paso en la despenalización del aborto. El País Digital, Sociedad, disponible en: https:// elpais.com/sociedad/2019/09/25/actualidad/1569446187_137012. html. 
Esta revista forma parte del acervo de la Biblioteca Jurídica Virtual del Instituto de Investigaciones Jurídicas de la UNAM

RibSTEIn, L. y KoBAyASHI, B. (2006). The Economics of Federalism. Ed. por George Mason Law \& Economics Research, Paper 06-15, Illinois Law and Economics Working Papers, Serie LE06-001.

Rivera SuÁrez, J. y RiVERA SuÁrez, M. (2014). La conformación del Senado mexicano en el Siglo XXI. Análisis socio-jurídico de la fórmula para asignar los escaños (la reforma política pendiente). Alegatos, 86, enero-abril, disponible en: https://biblat.unam.mx/hevila/Alegatos/2014/no86/6.pdf.

Ruiz Tena, C. y D’Alessandro, M. (2020). La innovación política desde los feminismos. Estrategias de incidencia para la legalización del aborto en Argentina. Asuntos del Sur y Economía Femini(s)ta, disponible en: https://www.mujeresactivando.org/wp-content/uploads/2020/06/in novacion_politica_ffeminismo.pdf.

Smulovitz, C. (2015). ¿Quién paga por los derechos en las provincias argentinas? El caso de las leyes de violencia familiar. Desarrollo Económico, Revista de Ciencias Sociales, 55, 216.

STEPAN, A. (1998). Democracia y federalismo. Un análisis comparado. Rivista Italiana di Sciencia Política, 28, 1. Trad. de C. Carrizo, disponible en: https://unpabimodal.unpa.edu.ar/bibliografia/00-A0184/00A0184.pdf

TARR, G. A. (2001). Federalism, Subnational Constitutionalism and Protection of Minority Rights. Preparado para la Conferencia "Federal Arragements, Subnational Constitutions and the Protection of the Rights of Minorities in Europe", Seiseralm, Alpe di Suisi, Italia.

Vicente, E. y OTÓN OLIVERI, P. (2018). La legalidad no es suficiente. El impacto del fundamentalismo y las políticas Trump sobre el acceso al aborto en Puerto Rico y otros países. En Bergallo, P. y Jaramillo SIERRA, I. C. (comps.), El aborto en América Latina. Estrategias jurídicas para luchar por su legalización y enfrentar las resistencias conservadoras. Buenos Aires: Siglo XXI.

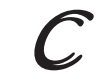

